\title{
Measuring peak expiratory flow in general practice: comparison of mini Wright peak flow meter and turbine spirometer
}

\author{
Kevin P Jones, Mark A Mullee
}

\begin{abstract}
Objective-To compare measurements of the peak expiratory flow rate taken by the mini Wright peak flow meter and the turbine spirometer.

Design-Pragmatic study with randomised order of use of recording instruments. Phase 1 compared a peak expiratory flow type expiration recorded by the mini Wright peak flow meter with an expiration to forced vital capacity recorded by the turbine spirometer. Phase 2 compared peak expiratory flow type expirations recorded by both meters. Reproducibility was assessed separately.
\end{abstract}

Setting-Routine surgeries at Aldermoor Health Centre, Southampton.

Subjects-212 Patients aged 4 to 78 presenting with asthma or obstructive airways disease. Each patient contributed only once to each phase (105 in phase 1, 107 in phase 2), but some entered both phases on separate occasions. Reproducibility was tested on a further 31 patients.

Main outcome measure-95\% Limits of agreement between measurements on the two meters.

Results $-208(98 \%)$ Of the readings taken by the mini Wright meter were higher than the corresponding readings taken by the turbine spirometer, but the $95 \%$ limits of agreement (mean difference (2 SD)) were wide ( 1 to $173 \mathrm{l} / \mathrm{min}$ ). Differences due to errors in reproducibility were not sufficient to predict this level of disagreement. Analysis by age, sex, order of use, and the type of expiration did not detect any significant differences.

Conclusions-The two methods of measuring peak expiratory flow rate were not comparable. The mini Wright meter is likely to remain the preferred instrument in general practice.

\section{Introduction}

Most hospital doctors use the large and rather expensive Vitalograph spirometer to assess basic lung function and may use the dial type Wright peak flow meter to measure peak flow. Until recently, however, general practitioners were much more likely to use the inexpensive mini Wright peak flow meter as their only spirometric aid. This may alter with increased use of the inexpensive award winning turbine spirometer. In its most basic form the spirometer measures only forced expiratory volume in one second and forced vital capacity, but the more sophisticated forms can measure peak expiratory flow rate and percentages of predicted values. The dial type and mini Wright peak flow meters have been compared previously, ${ }^{1}$ and the turbine spirometer has been compared with the Vitalograph spirometer, ${ }^{23}$ but there has not been a comparison of the two instruments most likely to be used in general practice. Retrospective data from a community survey of asthmatic patients suggested that the peak flow readings obtained with the turbine spirometer and the mini Wright peak flow meter may not be comparable (K P Jones, unpublished data). We therefore conducted a prospective study in a general practice setting.

\section{Patients and methods}

We measured the peak flow rates of 212 patients who had asthma or obstructive airways disease during their routine visits to Aldermoor Health Centre. The patients' age and sex were recorded, and the order in which the two instruments were used was decided randomly by drawing allocation cards from a shuffled pack. As the method of blowing required for recording peak flow differs from that needed for measuring forced vital capacity results were gathered in two phases. Phase 1 (105 patients) compared values for peak flow, which were derived from forced vital capacity type exhalations measured with the turbine spirometer with peak expiratory flow rate type exhalations measured with the mini Wright meter, and phase 2 (107 patients) compared measurements of peak expiratory flow rate type exhalations from both instruments. In phase 2 the best value of three attempts for each meter was recorded, but in phase 1 the first good attempt was accepted. This was to prevent fatigue from the forced vital capacity manoeuvres. Some of the patients in phase 1 also completed phase 2 , but this was carried out on a subsequent visit to the surgery. To assess the reproducibility of the results from the two meters a further 31 observations were made over two weeks in which two readings were recorded with each meter. Subjects were recruited similarly to those in the main part of the study.

Agreement and reproducibility between the two meters was assessed by the statistical methods proposed by Bland and Altman. ${ }^{4}$ The statistical package for the social sciences (SPSS/PC +$)^{s}$ and Microsoft Chart were used to analyse and plot the data.

\section{Results}

We studied 130 males and 82 females (mean age $40 \cdot 4$ years, range 4-78 years). Figure 1 shows the peak expiratory flow rates recorded with the two meters. In $208(98 \%)$ cases the turbine spirometer gave lower readings than the mini Wright meter. Figure 2 shows the difference between the values for peak expiratory flow rate recorded by the two meters plotted against the mean of the two values. This shows that there was considerable disagreement between the two meters, with a maximum discrepancy of $282 \mathrm{l} / \mathrm{min}$. No obvious relation was found between the difference and the mean values for peak expiratory flow rate.

The bias, estimated as the mean difference $(\mathrm{d}=$ $87 \cdot 13,95 \%$ confidence interval $81 \cdot 3$ to $92 \cdot 96$ ) and the standard deviation of the differences $(S D=43.03)$ were used to calculate the $95 \%$ limits of agreement $(d \pm 2 S D)$. 


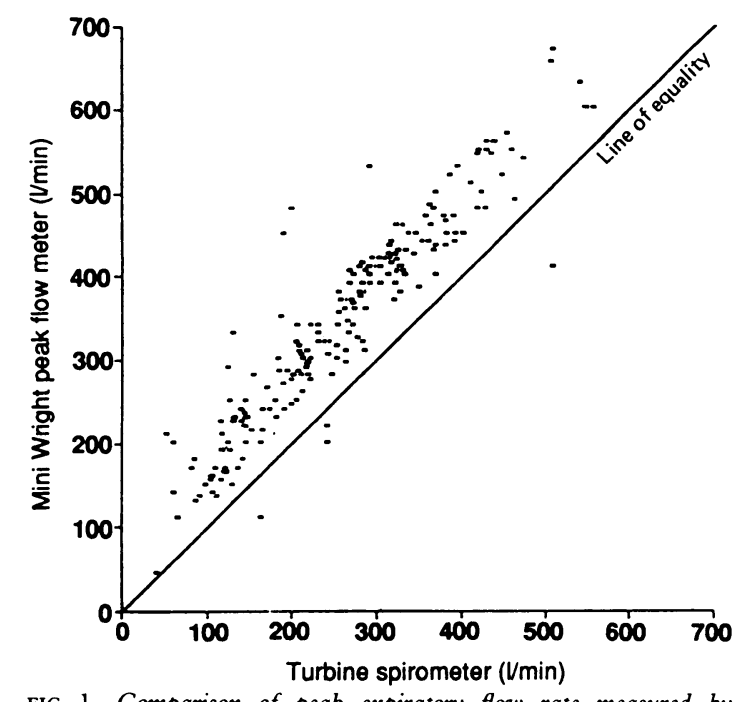

FIG 1-Comparison of peak expiratory flow rate measured by mini Wright peak flow meter and turbine spirometer

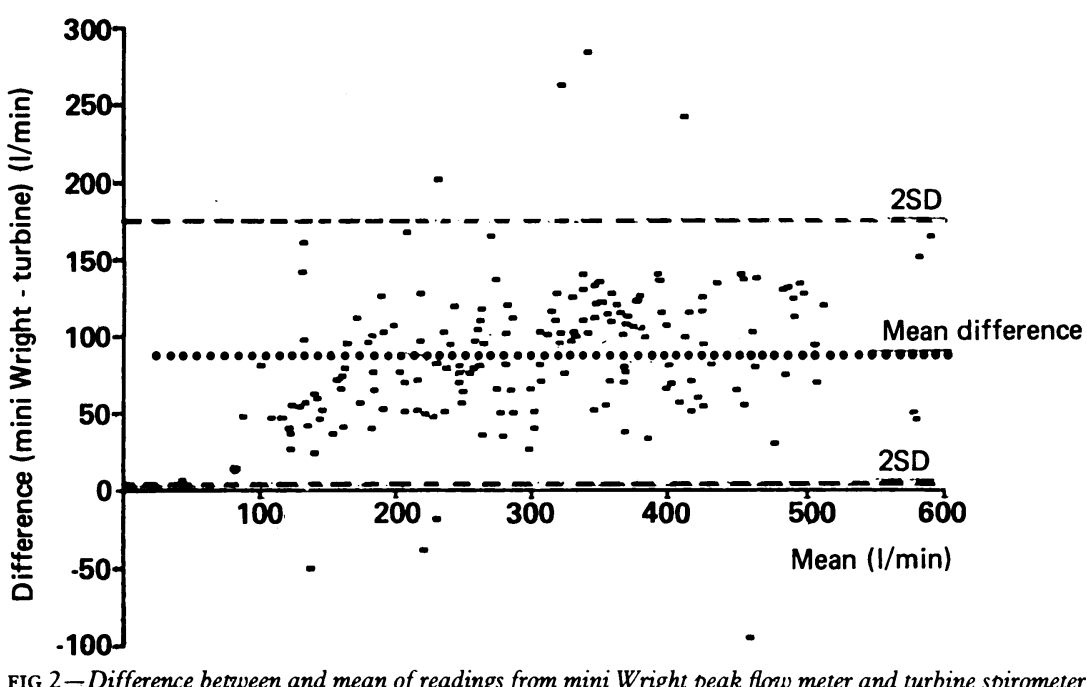

These limits indicate that the readings from the mini Wright meter may be between $1.07 \mathrm{1} / \mathrm{min}(95 \%$ confidence interval -9.02 to 11.6 ) and 173.19 $1 / \mathrm{min}(163 \cdot 1$ to $183 \cdot 28)$ above those from the turbine spirometer.

Neither the order of use of the meters nor the sex of the patient significantly affected the mean difference between the peak expiratory flow rates measured by the mini Wright meter and the turbine spirometer $(t=$ $0.84, \mathrm{p}=0 \cdot 40, \mathrm{df}=195$ for order of use and $t=0 \cdot 14, \mathrm{p}=$ $0.89, \mathrm{df}=210$ for the sex of the patient). The 105 observations from phase 1 were compared with the 107 observations from phase 2 by the $t$ test. No significant differences were found $(t=0.23, \mathrm{p}=0.082, \mathrm{df}=210)$, which suggested that the type of exhalation did not affect the reading from the turbine spirometer. The coefficients of reproducibility ${ }^{4}$ were $54.51 / \mathrm{min}$ for the mini Wright meter and $39.0 \mathrm{l} / \mathrm{min}$ for the turbine spirometer.

\section{Discussion}

We found that the turbine spirometer gave consistently lower readings than the mini Wright peak flow meter. The $95 \%$ limits of agreement were unacceptably wide ( 1 to $173 \mathrm{l} / \mathrm{min}$ ) for clinical purposes, indicating that the two could not be used interchangeably. The $95 \%$ confidence interval of the estimates of bias and the limits of agreement were fairly narrow, suggesting that the estimates were quite precise.

We considered two possible explanations for the differences between the instruments. The first was that fatigue from repeated forced expirations might be a contributing factor. Randomly allocating the order in which the meters were used allowed us to analyse this, and we found no differences. The second possible explanation concerned the type of expiration measured by the two instruments. Arguably, the peak flow attained with an expiration to residual volume (forced vital capacity manoeuvre) might be different from that resulting from a shorter expiration (peak expiratory flow rate manoeuvre). Unlike earlier studies ${ }^{3}$ we did not find any difference between the two types of exhalation.

As the two instruments are not interchangeable it is important to consider which of them might be better. This assessment is based on accuracy and cost. Although the turbine spirometer is much cheaper than other spirometers, such as the Vitalograph, it costs about $£ 400$ (depending on the version) and is more expensive than the mini Wright meter, which costs about $£ 10$ (depending on source).

Reproducibility could not be included in the analysis of the main study because in each case the best of three readings was taken and the other two readings were not recorded. The smaller series of 31 patients indicated a small advantage in favour of the turbine spirometer, but the significance of this is difficult to evaluate.

The mini Wright meter, first described by Wright in $1978,{ }^{6}$ was compared with the standard Wright meter when it was launched in the late 1970s. ${ }^{17}$ The statistical methods suggested by Bland and Altman ${ }^{4}$ were not used in these studies, but biases estimated at $3 \%^{1}$ and $38 \mathrm{1} / \mathrm{min}^{7}$ were thought to be clinically acceptable and similar to variations between different standard Wright meters. Small variations between instruments were noted with the mini Wright meters but were not regarded as clinically important. Higgs showed that comparing the two types of Wright meter gave a slightly $\mathrm{S}$ shaped curve rather than a linear plot. ${ }^{8}$ Comparison between different mini Wright meters gives parallel $\mathrm{S}$ shaped plots. The mini Wright meter is available in standard and low range models. Usherwood compared the two models in children and found that the models were not interchangeable. ${ }^{9}$

Two studies compared the turbine spirometer with the Vitalograph, ${ }^{23}$ one of which also included the standard Wright peak flow meter. The same method of statistical analysis was used as in our study. The $95 \%$ limits of agreement for forced expiratory volume and forced vital capacity (comparing the Vitalograph with the turbine spirometer) and for peak expiratory flow rate (comparing the standard Wright meter with the turbine spirometer) were wide $( \pm 52 \cdot 2 \mathrm{l} / \mathrm{min}$ for peak expiratory flow rate). Gunawardena et al thought that this might be due to the different types of expiration used, ${ }^{2}$ but we have not substantiated this.

There are problems, therefore, in comparing readings of forced expiratory volume, forced vital capacity, and peak expiratory flow rate measured with different instruments. Within general practice it is probably better to have several mini Wright meters available for loan to patients than to have one expensive turbine spirometer. Accuracy will, however, be improved if the standard and low range mini Wright meters are not interchanged and if the same meter is used for the same patient whenever possible.

In conclusion, the two instruments compared in this study did not produce comparable peak flow readings. The mini Wright peak flow meter tended to give higher values, but predicting readings on the mini Wright meter from those on the turbine spirometer was unsatisfactory, as shown by the wide $95 \%$ limits of agreement. Interestingly, the method of blowing did not seem to be important. Although the turbine spirometer is sufficiently cheap to be affordable by general practices, the mini Wright meter is likely to 
remain the preferred instrument to measure peak flow rates. Whether knowledge of values for forced expiratory volume in one second and forced vital capacity in addition to that of peak expiratory flow rate is helpful to general practitioners is a question that will determine the relevance of the turbine spirometer in primary care.

We thank Miss L A Izzard and Mrs M Dracass for typing the manuscript; Clement Clarke for providing the peak flow meters; and Professor John Bain, Professor Stephen Holgate, and Dr Mike Campbell for their useful comments. This paper was presented in poster form at the winter meeting of the British Thoracic Society. KPJ was a Sir Jules Thorn research fellow.
1 Oldman $\mathrm{HG}$, Bevan MM, McDermott $M$. Comparison of the new miniature Wright peak flow meter with the standard Wright peak flow meter. Thorax 1979;34:807-8.

2 Gunawardena KA, Houston K, Smith AP. Evaluation of the turbine pocket spirometer. Thorax 1987;42:689-93.

3 Hosie HE, Nimmo WS. Measurement of $\mathrm{FEV}_{1}$ and FVC. Comparison of a pocket spirometer with the Vitalograph. Anaesthesia 1988;43:233-8.

4 Bland JM, Altman DG. Statistical methods for assessing agreement between two methods of clinical measurement. Lancet 1986; i:307-10.

5 Norusis MJ. The SPSS guide to data analysis for SPSS/PC+. Chicago: Statistical Package for the Social Services, 1989.

6 Wright BM. A miniature Wright peak-flow meter. Br Med f 1978;ii:1627-8.

7 Perks WH, Tams IP, Thompson DA, Prowse K. An evaluation of the miniWright peak flow meter. Thorax 1979;34:79-81.

8 Higgs CMB. Studies on the perception of asthma [MD Thesis]. Cambridge: University of Cambridge, 1987: 108 pp.

Usherwood TP, Barber JH. Discrepancy between standard and low range mini Wright peak flow meters. Br Med f 1986;292:523-4.

(Accepted 30 April 1990)

\title{
Screening in Practice
}

\section{Breast cancer screening and the primary care team}

\author{
Joan Austoker
}

The National Breast Screening Programme, which is currently being implemented in the United Kingdom, provides an important new challenge to the whole primary care team. The aim is to reduce mortality from breast cancer through early diagnosis by mammography. The programme follows the recommendations made in the Forrest report ${ }^{\prime}$ : women aged $50-64$ will be screened; women aged 65 and over will be screened on request; women under 50 will not be offered routine screening. Screening by single oblique view mammography is to take place at three year intervals. These guidelines are being kept under review and are the subject of national research trials.

\section{Practical contribution of the primary care team}

Unlike other screening programmes such as cervical cytology, for breast screening the new general practitioner contract does not provide financial inducements to enlist the cooperation of general practitioners. In the terms of the contract all that is required for breast screening is for the general practitioner, where appropriate, to seek details from newly registered patients or patients not seen within three years in respect of tests carried out for breast cancer. ${ }^{2}$ But for the National Breast Screening Programme to be successful the contribution and cooperation of primary care teams is essential. Primary care teams can help to improve the quality of the programme, increase uptake, and provide information and counselling related to all aspects of the programme.

If women are to be given accurate and appropriate information and advice it is important for all members of the primary care team to understand the organisation of the programme. For this purpose each practice in Britain should receive an information pack from the Cancer Research Campaign when the practice starts to participate in the programme. ${ }^{3}$ More important, however, is that each practice should be visited by representatives from the screening office in order to discuss breast screening in general and the local arrangements for screening the practice in particular. Good communication between practices and the screening office is essential. Practices should be well prepared in advance, understand the procedures, and know the time schedule for the entire screening process. Arrangements should also be made for referring women with abnormalities detected on screening. Ideally this should include prior consent by the general
The practical contribution of the primary care team

Quality:

- Improve acceptability of the programme

- Make appropriate referral arrangements

- Evaluate primary care team involvement

Uptake

- Check prior notification lists

- Encourage attendance

- Provide practical advice

- Allay fears

- Discuss screening with non-attenders

Information and counselling

- Answer general inquiries

- Advise ineligible women

- Discuss the implications of recall for further investigation

- Discuss the implications of a biopsy

- Discuss treatment options

- Discuss screening with non-attenders

practitioner for the automatic referral of all women with "abnormal" mammograms to the specialist multidisciplinary team at the assessment centre for further investigation to confirm normality or make a definitive diagnosis of cancer (see below). ${ }^{4}$ This is particularly important for the evaluation of impalpable lesions. Speed in referral for each stage of investigation is vital, and arrangements must give priority to this.

\section{The breast screening procedure}

The screening procedure can be divided into three screening stages (identification and invitation, mammography, further investigation) and treatment. This is followed by routine recall. Figure 1 shows these stages. The estimated annual throughput for each stage when the programme is fully operational is shown in the table.

In an undertaking on this scale quality assurance is essential to ensure that uniformly high standards are maintained at all times, in all places, and at all stages of the procedure. This includes the need to increase attendance rates; monitor consumer satisfaction; assure high quality mammography, pathology and treatment; 